\title{
FIRE CONTROL EQUIPMENT AND METHODS ${ }^{1}$
}

\author{
BY S. W. SCHORTINGHUIS \\ Manitoba Forest Service, Winnipeg, Manitoba \\ INTRODUCTION
}

The trouble with forest fire control in Canada is that not a large enough percentage of our fires are confined to a small area, and that efficiency in control deteriorates rapidly in proportion to the number of fires burning and men employed. It is easy to state the problem, but the underlying causes and solutions cover the whole broad and complex field of forest fire protection. The keynote of the problem, however, is "inadequacy" - inadequacy of funds, staff, planning, training and equipment.

The different phases of protection cannot be developed in succession; the acquisition of equipment, for example, cannot wait until the pre-suppression aids have been amply provided. To build an organization capable of keeping our fire losses to a reasonable figure is a slow, costly business. It is no wonder that among the general public, and to a lesser extent in forest industry, and even within our own ranks, there are those who over-emphasize the sensational in fire control. Research and development have done, and will continue to do, much towards better fire protection. We must certainly not overlook any tool or other aid which can help to reduce fire losses, but we need a strong trained organization to protect our forests, an organization capable of standing up to the strain of a serious fire situation from the top down to the man handling a hose nozzle or shovel.

The more specialized our tools and techniques become the greater need there is for this framework of good staff, well administered and properly trained. Just as a good football backfield is helpless behind a poor line, so are special techniques largely wasted when used by an inadequate organization.

The size and effectiveness of fire protection organizations vary across Canada. Also, forest values, fire risk and hazard and differences in climate and terrain vary from region to region. Our problems, however, are fundamentally the same.

Incomplete utilization and inadequate silviculture in our forests are also placing a very heavy load on those of us charged with protection. Both industry and the forestry profession must increase the output from our forests. Better silvicultural practices will mean increased costs, but these can be partially or wholly recovered by decreased fire losses.

Hand Tools

\section{EQUIPMENT}

Let us look at the tools and techniques which we now have, but which we do not use as often or as effectively as we should.

No matter how far we advance in fire suppression, the lowly hand tool will always be with us. As a fire situation develops we find our trained personnel and our special equipment spread out very thin. Sooner or later we extend a welcome hand to the untrained fire fighter who is capable of

1 Paper presented at the fortieth annual meeting of the Canadian Society of Forest Engineers, Fredericton, N.B., October 4 to 7,1948 . 
using only simple hand tools. Also, for quick initial action, and throughout the history of almost every fire, hand tools are employed to a larger or lesser degree. Many of us in Canada are overlooking useful tools such as the Pulaski tool and several rakes and beaters which have been thoroughly tested and are being used by protection organizations in the U.S.A. There should be greater diversity in hand tools for use in specific areas.

Those of us who do not employ the "one lick method" and other means of hastening control can only justify this because our suppression crews are not sufficiently trained to take advantage of these tested methods of gaining improved efficiency. Until we exploit the full use of hand tool techniques, we are not getting the most out of the staff and equipment we have, and, therefore, are not justified in looking for more complicated tools until we rectify this deficiency in our organizations.

Pamps

Gasoline-powered pumps are versatile tools suited for most areas, and for suppression of large and small fires. We can now secure reliable pumps with most of the special attachments needed. The emphasis given by the forestry profession to the design of pumps has aided in bringing about improvernents in present day models. I feel that we can now largely depend on manufacturers to maintain improvements through competition. Emphasis should continue to be on making comparative tests of pumps, hose and attachments, and improvements in the field of hose maintenance and special attachments.

Mecbanical Equipment

Mechanical equipment is constantly taking a more important place in fire suppression, although its use is limited by terrain, transportation difficulties and cost.

The types of equipment used in fire suppression were principally designed for the construction and logging industries. In order to move earth and logs cheaply, many special types of primary movers and numerous designs of allied equipment and attachments are on the market. As these machines become more specialized for earth moving or logging they usually become less suited for fire suppression work. It is, therefore, very necessary that our profession keep up-to-date with tractor and tractor-powered equipment, and that there be more and more research and development in respect to the design of allied equipment suited for our purposes. For a long time to come I feel that we should accept the present designs of tractors and concentrate on special tractor-powered equipment.

For example, scrapers would be useful if a mouldboard could be installed in the bucket, so that we could plough a continuous furrow. When it is considered that scrapers can cut stumps up to 10 inches diameter, such a tool seems to have possibilities for the establishment of a wide trench to mineral soil quickly. Several modifications have already been made to dozers in connection with land clearing, and some of these modifications would, I think, improve this tool for fire fighting.

Light Tractors

Rubber-wheeled tractors are being improved very rapidly, and are invading a field held solely by crawler type machines until recently. Even farm 
tractors have a place in fire fighting. Such units, capable of travelling up to 20 miles per hour, equipped with hydraulic controls and a general purpose plough, are excellent one-man suppession units for open pine stands on sandy soil, and useful on the fringes of settlement in the semi-open country on which so much of our suppression occurs. Their usefulness is limited by terrain and cover type, but they are good inexpensive tools in suitable localities. The heavier industrial wheeled tractor has, of course, a wider use. It is interesting to note that these machines are being used by contractors with dozer and scraper equipment. I think that wheeled tractors will generally be found more useful for fire line construction than the small gasoline crawler type machine recently developed will prove to be.

\section{Heavy Tractors}

Large diesel tractors are now mounted on wheels. They compete with heavy crawler types, but I do not think that the ease of transportation will outweigh the disadvantages of this design over the heavy crawler tractor in typical forested country.

For Manitoba conditions we like to employ a 60-90 h.p. crawler tractor with dozer in front of a 45 h.p. one. We think this speeds up line construction. As far as techniques are concerned we haven't really developed any. The machines work as close to the fire as possible, sometimes they even shove in burning material. In view of the fact that tractors are usually late comers to the fire, most of the work done is along the back and sides of fires being stopped by other means. Considerable care is necessary in the employment of tractors. Where possible, two machines should work together, as one alone is apt to get bogged. Even wide gauged machines are very sensitive to wet terrain, especially if they are working, and it is best to keep them out of such places.

Dozers are operated either by hydraulic or cable equipment. Arguments as to the merits of these go on endlessly, reminiscent of those heard in connection with snowshoes, axes, etc. We have settled on the hydraulic controls.

We fit dozers with a front-end power take-off and reserve the rear mounting for either a power take-off or power control unit for use with scrapers, etc.

Ploughs

Although we use ploughs, I do not know of any design which I can recommend. The 24" high beamed breaking plough works quite well with light tractors in places where the underbrush is not heavy, but it is limited in its performance. Goose-necked ploughs are difficult to control and V ploughs also have several disadvantages. Disc-type ploughs do excellent work on light soils and clean forest floors, but cannot be used to advantage in underbrush, thick timber, etc. Therefore we use several designs of ploughs in different districts, without being convinced that we have found the right type anywhere.

Other Types of Equipment

We do not use draglines, trenchers or mechanical equipment other than tractors on fires in Manitoba. Although there are times and places where 
such items could be used, we feel that their use is too limited for us to consider them for other than construction work at this time. Truck mounted draglines may appear to be useful, but I am of the opinion that they are too sensitive to terrain to be suitable for our purpose.

\section{TRANSPORTATION}

For transporting mechanical equipment it is desirable to have wheels of the trailer mounted in line with those on the truck. Also, because much travel is on poor roads with steep grades, it is important to have a truck of sufficient power. The securing of platform equipped trucks of a size to carry heavy tractors is possible, but means a large investment for a unit which is very limited for other use.

\section{Full Use of Mechanical Equipment}

Tractors are expensive to buy, maintain and transport. In order to justify their purchase, protection organizations should incorporate their use with the closely allied field of forest improvements. Unless this be done, by using stand-by suppression crews with these units employed on road and trail constructions, permanent fire guards, etc., most organizations are better advised, in my opinion, to concentrate on other fields of fire suppression and other types of equipment.

\section{AIRCRAFT}

Much of the protected area of Manitoba lies in the Pre-Cambrian shield, where transportation is mostly with aircraft. This means that many tools are denied to us throughout a large part of our protected area, and hand tools, pumps, sectional canoes and other light equipment only can be used. Some years ago the Air Service was divorced from the Forest Service, and made a separate Branch of the Department, although we still are its best customer, and fire protection has absolute priority. Because the scope of the Air Service has been extended by providing transportation for other Government Departments and non-profit flying, the expansion of this Service has been much faster and greater than would have been possible for straight Forest Service flying.

We have found flat equipped single-engined monoplanes best for our use, and we are staying away from the very light and the heavier models. We like the Norseman, mark- $V$ when these are supplemented by the Fairchild Husky and the new Beaver. The versatile Husky, capable of carrying long awkward loads, is useful in cargo dropping and in numerous other ways. We wish that it had more power. The de Haviland Beaver has wonderful take-off performance. It is somewhat restricted as to cargo space, and we have not operated these machines long enough to find out if its light construction will mean higher maintenance costs, In the meantime this machine is greatly affecting speed of suppression by making accessible lakes which previously had to be ignored.

If the use of dry ice becomes standard practice our aircraft will have to fly at altitudes of over ten thousand feet. This will mean the provision of oxygen. The instruments and knowledge necessary for blind flying will also be needed for this type of flying. 
We have tested cargo dropping methods, and have adopted the equipment designed by the Alberta Forest Service. We feel that cargo dropping rather than parachuting fire fighters is the better field for us to test in Manitoba, at this stage of our development.

Just as we became interested in helicopters the two commercial craft available were washed out. This type of aircraft undoubtedly has great possibilities, but until this machine is further developed we are content to have it tested by organizations with more money and personnel to spare for these purposes than we have.

\section{Conclusion}

The whole field of fire control equipment and methods is by no means covered in this paper. Radio, which could well have been included, has been left out as it deserves separate and special treatment. Also, wetting agencies, the use of chemicals, special pumping techniques and attachments are not mentioned, as I feel that these fields have been well covered by those who have done actual research.

While we fight fire, often large ones, with simple tools we must be building solidly so that we can incorporate known techniques and equipment in our work as quickly as is practical. We must develop new equipment and techniques, but we must be sure that we are organized for proper and most efficient use.

There is no cheap short-cut to adequate fire protection, but we must be sure that the long, hard trail ahead of us is clearly marked, and that we use every means of hastening our progress to the goal of allowable fire losses. 